\title{
ONE-PERCENT PENTACHLORPHENOL PROTECTS WOOD AGAINST DRY-WOOD TERMITE ATTACK FOR MORE THAN II YE.ARS
}

Pentachlorphenol is the standard by which other chemicals are judged for effectiveness and permanence of impregnation in wood for protecting it from attack by fungi and insects. For commercial use it is usually sold as a 5-percent solution, which is presumed to give an ample margin of safety even for external applications in contact with the soil or exposed to rain and weather. For use on furniture and interior trim, ordinarily not exposed to rain but, of course, susceptible to slow volatilization in the air, extensive tests have been conducted on the permanent effect of this and other chemicals in resisting attack by the West Indian dry-wood termite, Cryptotermes brevis Walker ${ }^{1}$. A test sample of West Indian Birch, Bursera simaruba (L.) Sarg., impregnated with 0.2 percent of technical pentachlorphenol (Monsanto) on January 18, 1944, was attacked by the termites after only 13 days, but 273 days elapsed before the sample treated with 0.5 percent was eaten. After 337 days, the 1-percent sample had a distinct gouge in the face, but the termites did not subsequently increase the size of this gouge. From time to time in succeeding years, this sample was repeatedly placed in test with fresh termites, but they completely ignored it, if not at times derisively using it as a repository for their excrement pellets.

Late in the summer of 1955 , more than 11 years from the date of the original impregnation of this sample, the termites attacked it from the bot-

1 Wolcott, G. N., Organic termite repellents tested against Cryptotermes brevis Walker, J. Agr. Univ. P. R., 39 (3) 115-49, (ref. 4.) July 1955.

tom end and made a deep tunnel into its interior. When wedged tightly against another piece of wood so that the bottom end was covered, fresh termites made another tunnel into the top end, a tunnel so deep that several termites could take shelter inside of it. The original gouge on the face still has not been enlarged, but with deep tunnels from either end, it must be conceded that in somewhat over 11 years after impregnation, 1-percent pentachlorphenol, as indicated by this test, is no longer effective in protecting susceptible wood against dry-wood termite attack. 